\title{
A resilient approach to modelling the supply and demand of platelets in the United Kingdom Blood supply chain
}

DOI:

10.1080/17509653.2021.1892548

\section{Document Version}

Accepted author manuscript

Link to publication record in Manchester Research Explorer

\section{Citation for published version (APA):}

Ejohwomu, O., Too, J., \& Edwards, D. (2021). A resilient approach to modelling the supply and demand of platelets in the United Kingdom Blood supply chain. International Journal of Management Science and Engineering Management, 16(2), 143-150. https://doi.org/10.1080/17509653.2021.1892548

\section{Published in:}

International Journal of Management Science and Engineering Management

\section{Citing this paper}

Please note that where the full-text provided on Manchester Research Explorer is the Author Accepted Manuscript or Proof version this may differ from the final Published version. If citing, it is advised that you check and use the publisher's definitive version.

\section{General rights}

Copyright and moral rights for the publications made accessible in the Research Explorer are retained by the authors and/or other copyright owners and it is a condition of accessing publications that users recognise and abide by the legal requirements associated with these rights.

\section{Takedown policy}

If you believe that this document breaches copyright please refer to the University of Manchester's Takedown Procedures [http://man.ac.uk/04Y6Bo] or contact uml.scholarlycommunications@manchester.ac.uk providing relevant details, so we can investigate your claim.

\section{OPEN ACCESS}




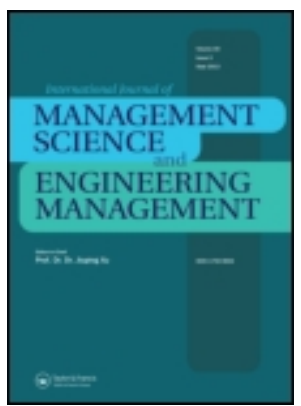

\section{A resilient approach to modelling the supply and demand of platelets in the United Kingdom Blood supply chain}

\begin{tabular}{|r|l|}
\hline Journal: & $\begin{array}{l}\text { International Journal of Management Science and Engineering } \\
\text { Management }\end{array}$ \\
\hline Manuscript ID & TMSE-2020-0121.R2 \\
\hline Manuscript Type: & Case Study \\
\hline Keywords: & $\begin{array}{l}\text { platelets, simulation, inventory management, optimisation, blood supply } \\
\text { chain }\end{array}$ \\
\hline \multicolumn{2}{|l}{} \\
\hline
\end{tabular}

\section{SCHOLARONE ${ }^{m}$ \\ Manuscripts}


A resilient approach to modelling the supply and demand of platelets in the United Kingdom Blood supply chain 


\begin{abstract}
The short shelf-life of platelets together with their stochastic demand and variable supply creates problematic decision making for inventory managers who seek to maintain optimal stock levels. This paper develops a novel simulation model that acts as a decision support tool for identifying optimal stock levels that would guarantee the availability of stock and, eliminate wastages and outages within the platelet supply chain. A multi-method approach is delineated upon that combines agent-based and discrete event modelling built on Anylogic software using data collected from typical UK Stock Holding Units (SHUs). The model simulates the demand and supply of 24 different platelet types broken down into their ABO and rhesus groupings and recommends the appropriate stock level at SHUs that will reduce expiries by $78 \%$ while simultaneously guaranteeing stock availability. This research not only represents the first attempt to fully understand the UK platelet supply chain but also presents an advanced simulation model that adopts a 'pull' system of platelet inventory management. Further, the concept of resiliency is integrated into the design of the solution methodology by testing the model behaviour in unexpected disruptions in the supply chain during an emergency case study.
\end{abstract}

Keywords: Blood supply chain, platelets, simulation, inventory management, optimisation. 


\subsection{Introduction}

The supply of blood products is irregular (due to the uncertainty of donor willingness) and its demand stochastic (Beliën \& Forcé, 2012) making it difficult to accurately forecast production and schedule blood donations (Samani et al., 2020). Therefore, inventory management seeks a trade-off between shortages and wastages to guarantee the availability of blood products while simultaneously minimizing expiries (Stanger, et al., 2012). Although more than a hundred different products can be extracted from blood, platelets, red blood cells and plasma are the most important components (Katsaliaki \& Brailsford, 2017). Platelets are particularly significant because they have multiple uses in chemotherapy, bone marrow transplants, treatment of coronary artery diseases and more recently, researchers have discovered its application in developing a Coronavirus (COVID-19) vaccine (Chang et al., 2020).

One challenge for inventory managers, however, is that platelets have the highest rate of perishability- with a short five to seven days storage shelf-life (Zahiri, et al., 2018). Indeed, in the USA and Western Europe, approximately $20 \%$ of platelets collected result in expiries (Rajendran \& Ravindran, 2020). Apart from wastages, unpredictable challenges caused by unplanned surgeries, natural disasters, equipment breakdown, war and labour strikes lead to significant disruptions and losses within the blood supply chain and consequently, unsatisfied demands (Haeri et al., 2020). It is crucial therefore to public health, that policies are adopted that assimilate the concept of 'resilience' (i.e. an innate ability to withstand large-scale disruptions) into planning and inventory management to remain reliable despite unexpected challenges (Rajendran \& Srinivas, 2020).

To resolve this aforementioned problematic public health conundrum and achieve equilibrium between blood products supply and demand, this study focuses on platelet inventory management and seeks to answer the following inductive questions: 1) What is the 
optimal level of platelet inventory that will meet demand and reduce shortages? 2) What is the impact of relying on hospital demand to make decisions on inventory levels at Stock Holding Units (SHUs) vis-à-vis depending on the supply side? 3) How can resilient inventory management decisions be made in the face of an emergency?

Although several authors have attempted to provide a solution to the platelet inventory management problem, Beliën \& Forcé (2012) report upon a discernable lack of fully scalable models (both mathematical and simulation) that provide clear demonstrable evidence of performance improvement in practice. Most innovative academic solutions are limited to theoretical contexts only (Stanger, et al., 2012a) and research into blood inventory management remains scant (Rajendran \& Srinivas, 2020). Within the specific area of platelet inventory management research, consideration of the different platelet categories, together with their $\mathrm{ABO}$ and rhesus groupings remains unexplored. Studies predominantly devote their analysis to one type of platelet product (Haeri et al., 2020), which is mostly apheresis platelets. Furthermore, integrating the concept of resiliency into the design of a solution methodology for platelet inventory management has not yet been fully addressed. Haeri et al (2020) conducted perhaps the closest match to this present study and considered different resiliency measures in the blood supply chain. However, their study (ibid) focuses on the design of the blood supply chain network. Consequently, this current research utilizes data collected from a real-life SHU in England to develop a pragmatic decision support tool that can be implemented in generating optimal stock levels. In addition to being the first attempt to fully understand the UK platelet supply chain, this novel study is also the first to propose a multi-product simulation model that advances previous simulation models viz.: 1) It analyses 24 different types of platelet categories broken down into apheresis, pooled and paediatric platelets, the different $\mathrm{ABO}$ categories and their rhesus groupings. While previous researchers have developed bespoke solutions for the blood supply chain, their focus has 
mainly been on red blood cells and apheresis platelets; 2) The simulation model was designed to operate based on a 'pull' system meaning that the stock levels at the SHU are influenced by hospital demands. The pull system facilitates elimination of wastage and reduction of cost (Lu \& Zheng, 2009) since the model's outputs inform production planning; 3) Substitution of platelet products is considered; 4) The model's resilience was tested in an emergency case study of a real-life SHU.

The rest of the paper is organised as follows: section 2.0. The platelet supply chain: a literature reviewsynthesises relevant literature on platelet supply chain; section 4.0. Materials and methods presents the case study; section 3.0. Case study description delineates the methodology utilised in this paper; section 5.0. Results presents the study's results and managerial insights inferred from these, and section 6 provides conclusions and signposts future opportunities for further research.

\subsection{The platelet supply chain: a literature review}

Extant literature on platelet supply chain optimisation reviewed illustrates that international studies have critically evaluated platelet inventory management optimisation approaches from various context-specific perspectives. Although early studies extend back to the $1960 \mathrm{~s}$ (Cohen \& Pierskalla, 1979; Osorio et al., 2015), the platelet supply chain has hitherto received scant academic attention until recent years (Blake, 2017).

Haijema et al. (2009) adopted Stochastic Dynamic Programming (SDP) with simulation to arrive at policies that they claim would lead to shortage levels of less than $1 \%$ and reduce wastages from $20 \%$ to $1 \%$ during Christmas, New Year's and Easter breaks. Due to the short shelf-life of platelets, these breaks may seriously affect the levels of shortages and wastages; making their findings particularly noteworthy. Van Dijk et al. (2009) ignored the stock age distribution and combined SDP with discrete event modelling to arrive at an 'order-up-to' rule for each day of the week. The major limitation of this study, however, was their 
oversight in the presentation of results. Blake (2009) points out this error and strongly contests the results of Van Dijk, et al. (2009), arguing that ignoring the age-distribution of stock yields inventory levels are not practical. Further, Abdulwahab \& Wahab (2014) analyzed the performance of the Canadian Blood Service and proposed a mathematical model based on approximate dynamic programming. The model examined different supply policies (circular, first-in-first-out (FIFO) and last-in-first-out (LIFO)), concluding that increasing the order delivery to two times per day and incorporating a strict FIFO policy produces minimal inventory shortages, minimum outdates and minimum average inventory. Katsaliaki \& Brailsford (2017) adopted a different approach and utilised discrete-event simulation. They (ibid), concluded that strict adherence to FIFO inventory policy and the introduction of two routine deliveries to hospitals (vis-a-vis one), would improve the system performance, arriving at the same conclusion as Abdulwahab \& Wahab (2014).

The World Health Organization (2011) guidelines recommend that adequate contingency plans should be implemented by blood centres for collection, processing and use of blood products during a pandemic. Rajendran \& Srinivas (2020), consider the effects of disruption on the supply chain and adopt mathematical modelling to develop inventory management policies that offer a trade-off between wastages and shortages. Haghjoo et al. (2020); Hosseini-Motlagh et al. (2020); Hamdan \& Diabat (2020) and Yaghoubi et al. (2020) made further contributions in developing solutions for optimising the supply chain under disruptions to minimize transportation, inventory and fixed costs as well as lower the rate of shortages and wastages.

\subsection{Case study description}

The National Health Services Blood and Transplant (NHSBT) is mandated to ensure that blood products are delivered to UK hospitals in a timely and sufficient manner. Approximately 28,000 units of blood and its components are collected weekly from fixed and 
mobile donation centres. The collected blood is then tested for ABO, rhesus grouping, infectious agents and viruses, and then processed in manufacturing centres (Baesler, et al., 2014). The three manufacturing centres within the UK (located in Manchester, Colindale and Bristol) centrifuge whole blood into the three major components: plasma, platelets and red blood cells. After processing, the blood components are stored in SHUs ready for issue when ordered by transfusion laboratory managers. The current approach for inventory management in the SHUs is to hold fixed stock targets that are reviewed every six months. This simplistic approach to inventory management of platelets tends to be time-consuming and makes it difficult to make production decisions that will result in optimal inventory levels. Since evidence-based inventory management is what leads to best practice in blood services, this study adopted one of the SHUs as a case study to illustrate the applicability of the developed simulation model and its solution approach for effective platelet inventory management.

\subsection{Materials and methods}

A mixed philosophical stance was adopted using interpretivism to analyse existing literature and justify the novelty of this present study (Roberts et al., 2018), and positivism (Edwards et al., 2020) to develop the simulation model. Within this overarching epistemology, a mixedmethod approach was adopted, incorporating both qualitative and quantitative techniques to comprehensively model the case study. This approach was implemented in five stages that were interrelated to each other; specifically, the output of one stage iteratively informing the next as illustrated in Figure 1.

$$
>>\text { Insert Figure } 1<<
$$

\subsection{Focus group discussions}

In this multi-level single case study, a non-probability sampling technique was used to constitute a focus group. The formation of the group, discussions and site visits to two of the three manufacturing sites occurred over twenty months; an extended period that was not only 
needed to negotiate research support but also secure a more comprehensive understanding of the operational activities of the SHU. This practical knowledge accrued was instrumental in developing the simulation model that accurately reflected reality. Focus group discussions were chosen because unlike interviews, they provide a more precise and clearly defined focus on the topic, enabling an interactive discussion between the participants (Pärn and Edwards, 2017). The focus group participants consisted of six senior staff members of NHSBT who are responsible for making decisions on the stock levels within the UK blood supply chain and had between 5 and 30-years' experience in blood manufacturing. Although a sample frame of ten staff was originally identified as relevant to the study, only six responded positively thus representing a $60 \%$ response rate. Semi-structured questions were used to guide interactions, and the ensuing discourse recorded, transcribed and analysed using NVivo.

\subsection{Developing the simulation model}

The simulation model was built on a multi-method approach combining both agent-based and discrete event modelling. This simulation model allows for the comparison of various inventory policy alternatives for the 24 different platelet products while supporting decision making in a stochastic environment by evaluating appropriate stock levels through what-if analysis (Terzi \& Cavalieri, 2004). Due to the complexity of the platelet supply chain, system behaviour cannot be accurately defined (Osorio et al., 2015). However, the key variables and dependencies within the system were identified. Agent-based modelling was chosen since it allows the system's 'global' behaviour to be understood by merging individual behaviours (Grigoryev, 2018). The variable 'hospital demand' was taken as an agent interconnected with another agent; the 'SHU' and the activities within the SHU such as 'replenishment orders', 'shortages', and 'wastages' modelled using discrete-event to show how they interact within the system. The model was developed on Anylogic software together with a Java code written to replicate the daily transaction activities at the SHU. 
Overall, the simulation model considers a 'pull' system where the stock levels are influenced by hospital demand (refer to Figure 2), eliminating the need to 'push' blood products to the hospitals.

$$
>\text { Insert Figure } 2<<
$$

\subsubsection{Data required by the model}

Data on hospital demands for the 24 different platelet categories by platelet type, quantity and blood group were obtained for the period between April 2017 and June 2019. Historical data was collected over two years to cover any seasonality that brings about variation in demand thus, presenting an accurate picture of the platelet supply chain. A source of uncertainty in this model (as replicated in a real system) is hospital demand for platelet units. Therefore, to incorporate variability in this demand, normal probability distributions at $95 \%$ confidence level were fitted to historical hospital demand data and analysed as input parameters for the model.

\subsubsection{Model assumptions}

The simulation was developed based on the following model assumptions: 1) Since the platelet shelf-life is seven days (Blake, 2017; Zahiri et al., 2018), the model assumes a shelflife of four days because processing at the manufacturing centre before the product arrives at the SHU takes up to three days; 2) A FIFO ordering policy is strictly adhered to at the SHU; 3) The SHU has enough staff and equipment to operate at increased capacity; and 4) Since the model scope does not extend to the manufacturing and donation centres, it is assumed that there is enough platelet supply to replenish the SHU's orders and the lead time is two days.

\subsubsection{Model behaviour}

The inventory levels of the 24 platelet types were modelled based on a continuous inventory review system; accounting for fluctuations in stock according to hospital demand and replenishment orders from the manufacturing centre (refer to Figure 3). Given the critical 
importance of having some blood products on hand (at all times) in the SHU, minimal safety stock and dynamic re-order points were defined for each platelet product at a $95 \%$ service level. The stock received from the manufacturing centre is stored in FIFO order at the SHU.

$$
>>\text { Insert Figure } 3<<
$$

Ideally, a hospital should be supplied with the same blood group of platelets that they have ordered from the SHU but this is not always possible due to product unavailability. Therefore, to manage the supply and demand, NHSBT may (in certain situations) request hospitals to accept a different ABO group from what was ordered. A Negative platelets for instance are the universal platelet type and are provided as a substitute for hospital demands. Each hospital request is first matched with the available stock in the SHU and the model allows for substitution for A Negative platelets if the same group demanded is unavailable at the time of the request. To reinforce this point, Participant A said:

"In basic what I am doing all the time is making more of the more valuable units. Like all the ones that are A Neg, I am just always making more... I am doing a lot of substitution to push all the products out..."

The model runs for a year, which is considered to be sufficient to capture the variability in the processes at the SHU - taking into consideration that one complete cycle of a platelet unit is only seven days.

\subsection{Model verification and validation}

The model was developed over four iterations based on feedback from professional practitioners in the UK blood supply chain. It was first built based on the authors' understanding of the platelet supply chain and thereafter modified to include ageing of the platelet units over four days, A Negative platelet substitution and incorporating a dynamic reorder point for each of the products. The model was verified as a true representation of the 
daily transactions at the SHU and its assumptions also viewed to be reasonable and realistic as indicated by participant E viz:

“The assumptions are sensible for the SHUs."

The model was populated with data from operations in the SHU in 2019 and was validated for reasonableness of its outputs by running the simulation 100 times. Harrell et al. (1995) highlight that this number of replications is ideal for ascertaining model output accuracy. The validation results showed no significant difference in the operational inventory and wastage levels (refer to Table 1).

$$
>\text { Insert Table } 1<<
$$

\subsection{Results}

The daily inventory levels derived from the simulation were compared to the actual target stock held at the SHU for July 2019 (specifically $1^{\text {st }}$ July to $28^{\text {th }}$ July 2019) and the variance determined as overstocked units. Due to the short shelf-life of platelets, this study describes an overstocked unit as any surplus platelet unit held within the SHU that is nearing expiry as confirmed by participant A, viz:

"I mean if a platelet is near day 7, it is an overstock as I am very unlikely to use it, I'm pretty sure I'm gonna expire it, I have zero probability to use it"

Since the level of inventory held at the SHU influences expiries and outages, it constituted the model's key performance indicator (KPI).

\subsection{Inventory levels}

Average daily inventory levels for the different platelet products were simulated based on hospital demand variations and the results determined over five iterations to capture the variability of the inputs. Simulated results were then analysed in comparison to the target inventory levels held in the SHU between $1^{\text {st }}$ July 2019 and $28^{\text {th }}$ July 2019. Although inventory holding costs are not considered in this model, holding higher inventory than 
necessary would certainly result in higher operational costs and subsequently increased wastages and shortages. The results illustrate a $14 \%$ overstock of apheresis platelets and pooled platelets, and an $82 \%$ understock of paedi platelets (refer to Table 2).

Due to the uncertainty in hospital demand for the products and their lifesaving property, the SHU holds excess inventory, especially for apheresis platelets, leading to wastages. Results indicate that by using a 'pull' system where hospital demand influences the inventory levels at the SHU, performance at the SHU is improved by reducing wastages by $78 \%$ and leading to financial savings. For instance, considering the cost implications of outdated A Negative apheresis platelets, the authors determine that the organisation loses approximately $£ 169,915$ from this one product since apheresis platelets are sold to hospitals at $£ 232.76$.

\section{$>$ Insert Table $2<<$}

\subsection{Outdated units}

The number of outdated units is an important KPI for blood supply chains. Since blood centres face the challenge of meeting demand without overstocking, the strategy adopted involves pushing platelets out of their system to avoid internal wastages. This is implemented by moving platelets to hospitals before they expire rather than awaiting hospital orders. Although this reduces internal wastages, it does not provide a solution to the systemic problem since wastages are only transferred to another part of the supply chain and not eliminated. This common practice was explicitly stated by Participant B who said:

"When there is something that's coming to end of shelf-life, they'll push it into that local hospital."

While overstocking may be a safety measure, wastage of units not only affects the operational costs of the SHU but is also a waste on the donor's time and effort (Stanger, et al., 2012). The wastage levels at the SHU when inventory is held at the units presented in Table 2 above were analysed in comparison to the actual monthly expiries at the SHU (refer 
to Table 3). Baesler, et al. (2014) maintains that an acceptable inventory policy is one that maximizes demand satisfaction while minimizing the levels of wastages. Adopting the 'pull' system in determining the inventory level as opposed to utilizing fixed targets as is the current case significantly reduces the overall level of expiries from $16.63 \%$ to $3 \%$ while guaranteeing the availability of stock when hospitals demand.

$>$ Insert Table $3<<$

\subsection{Shortages}

Shortages are not experienced when executing the model because it assumes that as soon as a replenishment order is made at the SHU, the order requests will be fulfilled by the manufacturing centre within 48 hours. In reality, this may not be possible because the collection side of the supply chain affects the availability of products at the manufacturing centre. However, considering a reasonable lead time of 48 hours and implementing the 'pull' system the shortages are reduced from $5 \%$ to $0 \%$.

\subsection{Model resilience}

The model must be resilient to unexpected challenges and disruptions in the supply chain (Sterbenz \& Smith, 2010) (such as equipment breakdown and natural disasters). Thus, resilience measures in the optimisation of inventory were taken into consideration to guarantee that hospital demand for platelet products would be met in periods of unexpected changes. The simulation model's resilience, in this case, was tested in the event of an emergency. The average hospital demands were multiplied by a factor of 10 to determine the behaviour of the model under extreme conditions. The simulation running in virtual time mode took 3 hours 24 minutes compared to the normal conditions that took 15 minutes. The results of the simulation were compared to the baseline scenario and revealed an appropriate increase in stock levels as expected and reasonable wastages. For instance, the inventory level for A Negative apheresis platelets increased to 117 units from 12 units when the 
demand increased from 4 to 40 units. Wastages, on the other hand, maintained at 0 units indicating the sensitivity of the model to computing wastages relative to the product life span when there is a surge in demand.

\subsection{Conclusion}

Besides providing an innovative tool for inventory management at NHSBT, this study represents the first attempt to fully understand the UK platelet supply chain. A multi-method simulation model was developed to capture the activities of a real-life SHU, verified and validated by experts in the UK platelet supply chain. The performance of the SHU can be improved by keeping the daily inventory levels as (12A-, 34A+, 0AB-, 3AB+, 1B-, 8B+, 9O-, $28 \mathrm{O}+)$ for apheresis platelets, $(7 \mathrm{~A}-, 33 \mathrm{~A}+, 0 \mathrm{AB}-, 1 \mathrm{AB}+, 1 \mathrm{~B}-, 11 \mathrm{~B}+, 7 \mathrm{O}-, 27 \mathrm{O}+)$ for pooled platelets and ( $\left.5 \mathrm{~A}-, 1 \mathrm{~A}+, 0 \mathrm{AB}-, 0 \mathrm{AB}+, 0 \mathrm{~B}-, 6 \mathrm{~B}+, 3 \mathrm{O}-, 1 \mathrm{O}^{+}\right)$for paediatric platelets while strictly adhering to the FIFO policy. This paper's outcomes provide insight into the trade-off between shortages and expiry rates, and can assist decision-makers in planning for optimised inventory management. Additionally, incorporating measures of resilience into decision making guarantees the availability of platelet products under peculiar circumstances.

A major limitation of this study is that operational costs were not included in the analysis. Further, while the model represents the SHU operating independently from the activities at the manufacturing centre and collection points, in real life, the decisions made in other parts of the supply chain may significantly affect the activities at the SHU. Future research could extend this model to incorporate the activities of the other parts of the supply chain to provide a robust solution to the platelet problem experienced. In particular, incorporating variability in supply may provide a better picture of shortages as a result of variable lead times. Future research could also incorporate stock holding costs in determining the optimal stock levels to illustrate the potential savings from the implementation of the optimal stock levels.

\subsection{Acknowledgements}


We express our gratitude to Professor Mike Murphy, Laura Hontoria Del Hoyo, Helen Livingstone and Jackie Morgan for their continuous support in providing data and enlightening information on the blood supply chain within the United Kingdom. Without their time and support, this project would not have been possible.

\subsection{Declaration of interest}

The authors hold no conflict of interest with the publication of the results included in this paper.

\section{References}

Abdulwahab, U., \& Wahab, M. I. M. (2014). Approximate dynamic programming modeling for a typical blood platelet bank. Computers and Industrial Engineering, 78, 259-270. https://doi.org/10.1016/j.cie.2014.07.017

Baesler, F., Nemeth, M., Martínez, C., \& Bastías, A. (2014). Analysis of inventory strategies for blood components in a regional blood center using process simulation. Transfusion, 54(2), 323-330. https://doi.org/10.1111/trf.12287

Beliën, J., \& Forcé, H. (2012). Supply chain management of blood products: A literature review. European Journal of Operational Research, 217(1), 1-16. https://doi.org/10.1016/j.ejor.2011.05.026

Blake, J.T. (2009). On the use of operational research for managing platelet inventory and ordering. Transfusion, 49(3), 396-401.

Blake, J. T. (2017). Determining the inventory impact of extended- shelf-life platelets with a network simulation model. Transfusion, 57(December), 3001-3008. https://doi.org/10.1111/trf.14305

Chang, L., Yan, Y., \& Wang, L. (2020). Coronavirus Disease 2019 : Coronaviruses and Blood Safety. Transfusion Medicine Reviews, 34(2), 75-80. https://doi.org/10.1016/j.tmrv.2020.02.003

Cohen, M. A., \& Pierskalla, W. P. (1979). Target inventory levels for a hospital blood bank or a decentralized regional blood banking system. Transfusion, 19(4), 444-454. https://doi.org/10.1046/j.1537-2995.1979.19479250182.x

Edwards, D.J., Rillie, I., Chileshe, N., Lai, J., Hosseini, M.R. \& Thwala, W.D. (2020), "A field survey of hand-arm vibration exposure in the UK utilities sector", Engineering, Construction and Architectural Management, 27(9), 2179- 2198. 
https://doi.org/10.1108/ECAM-09-2019-0518

Grigoryev, I. (2018). Anylogic in three days: A quick course in simulation modeling. https://www.anylogic.com/resources/books/free-simulation-book-and-modelingtutorials/.

Haeri, A., Hosseini-Motlagh, S. M., Ghatreh Samani, M. R., \& Rezaei, M. (2020). A mixed resilient-efficient approach toward blood supply chain network design. International Transactions in Operational Research, 27(4), 1962-2001. https://doi.org/10.1111/itor.12714

Haghjoo, N., Tavakkoli-Moghaddam, R., Shahmoradi-Moghadam, H., \& Rahimi, Y. (2020). Reliable blood supply chain network design with facility disruption: A real-world application. Engineering Applications of Artificial Intelligence, 90(April 2019), 103493. https://doi.org/10.1016/j.engappai.2020.103493

Haijema, R., van Dijk, N., van der Wal, J., \& Smit S. C. (2009). Blood platelet production with breaks: optimization by SDP and simulation. International Journal of Production Economics, 121(2), 464-473. https://doi.org/10.1016/j.ijpe.2006.11.026

Hamdan, B., \& Diabat, A. (2020). Robust design of blood supply chains under risk of disruptions using Lagrangian relaxation. Transportation Research Part E: Logistics and Transportation Review, 134(August 2019), 101764. https://doi.org/10.1016/j.tre.2019.08.005

Harrell, C.R., Bateman, R.E. \& Gogg, T.J. (1995). System improvement using simulation (3rd ed.). Orem (UT): PROMODEL® Corporation.

Hosseini-Motlagh, S. M., Samani, M. R. G., \& Homaei, S. (2020). Toward a coordination of inventory and distribution schedules for blood in disasters. Socio-Economic Planning Sciences, December 2019, 100897. https://doi.org/10.1016/j.seps.2020.100897

Katsaliaki, K., \& Brailsford, S. C. (2017). Using simulation to improve the blood supply chain Using simulation to improve the blood supply chain. 5682. https://doi.org/10.1057/palgrave.jors.2602195

Lu, N. Z. and X. (2009). Comparative study on push and pull production system based on Anylogic. International Conference on Electronic Commerce and Business Intelligence, 455-458. https://doi.org/10.1109/ECBI.2009.26

Osorio, A. F., Brailsford, S. C., \& Smith, H. K. (2015). A structured review of quantitative models in the blood supply chain: A taxonomic framework for decision-making. International Journal of Production Research, 53(24), 7191-7212. https://doi.org/10.1080/00207543.2015.1005766 
Pärn, E. A. and Edwards, D. J. (2017) Conceptualising the FINDD API plug-in: a study of BIM-FM integration. Automation in Construction, 80, pp. 11-21.

DOI:10.1016/j.autcon.2017.03.015

Rajendran, S., \& Ravindran, R. A. (2020). Multi-criteria approach for platelet inventory management in hospitals. International Journal of Operational Research, 38(1), 49-69. https://doi.org/10.1504/IJOR.2020.106360

Rajendran, S., \& Srinivas, S. (2020). Hybrid ordering policies for platelet inventory management under demand uncertainty. IISE Transactions on Healthcare Systems Engineering, 10(2), 113-126. https://doi.org/10.1080/24725579.2019.1686718

Roberts, C. J., Pärn, E. A., Edwards, D. J. and Aigbavboa, C. (2018) Digitalising asset management: concomitant benefits and persistent challenges. International Journal of Building Pathology and Adaptation, 36(2), pp. 152-173. DOI:10.1108/IJBPA-09-20170036

Samani, M. R. G., Hosseini-Motlagh, S. M., \& Homaei, S. (2020). A reactive phase against disruptions for designing a proactive platelet supply network. Transportation Research Part E: Logistics and Transportation Review, 140(May), 102008. https://doi.org/10.1016/j.tre.2020.102008

Stanger, S. H. W., Wilding, R., Yates, N., \& Cotton, S. (2012). What drives perishable inventory management performance? Lessons learnt from the UK blood supply chain. Supply Chain Management: An International Journal, 17(2), 107-123. https://doi.org/10.1108/13598541211212861

Sterbenz, J.P.G., Smith, P. (2010). Resilience and survivability in communication networks: Strategies, principles and survey of disciplines. Computer Networks, 54(8), 1245-1265. https://doi.org/https://doi.org/10.1016/j.comnet.2010.03.005

Terzi, S., \& Cavalieri, S. (2004). Simulation in the supply chain context : a survey. 53, 3-16. https://doi.org/10.1016/S0166-3615(03)00104-0

Van Dijk, N., Haijema, R., Van Der Wal, J., \& Sibinga, C. S. (2009). Blood platelet production: A novel approach for practical optimization. Transfusion, 49(3), 411-420. https://doi.org/10.1111/j.1537-2995.2008.01996.x

World Health Organization. (2011). Maintaining a safe and adequate blood supply during pandemic influenza: Guidelines for Blood Transfusion Services.

https://www.who.int/bloodsafety/publications/WHO_Guidelines_on_Pandemic_Influenz a_and_Blood_Supply.pdf

Yaghoubi, S., Hosseini-Motlagh, S. M., Cheraghi, S., \& Gilani Larimi, N. (2020). Designing 
a robust demand-differentiated platelet supply chain network under disruption and uncertainty. Journal of Ambient Intelligence and Humanized Computing, 11(8), 32313258. https://doi.org/10.1007/s12652-019-01501-0

Zahiri, B., Torabi, S. A., Mohammadi, M., \& Aghabegloo, M. (2018). A multi-stage stochastic programming approach for blood supply chain planning. Computers and Industrial Engineering, 122(February 2017), 1-14.

https://doi.org/10.1016/j.cie.2018.05.041 


\section{List of figures}

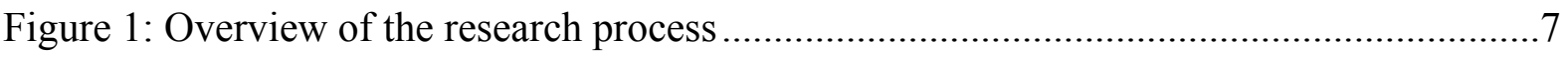

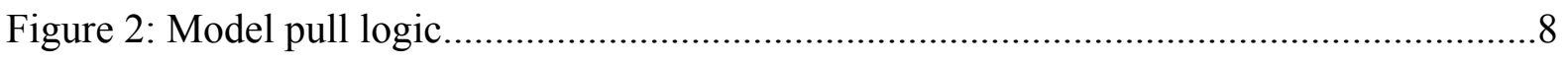

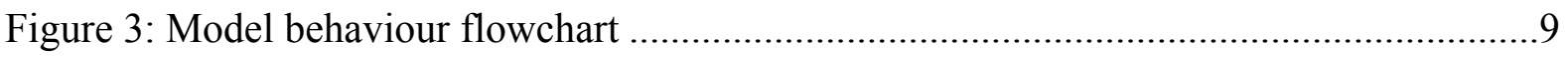




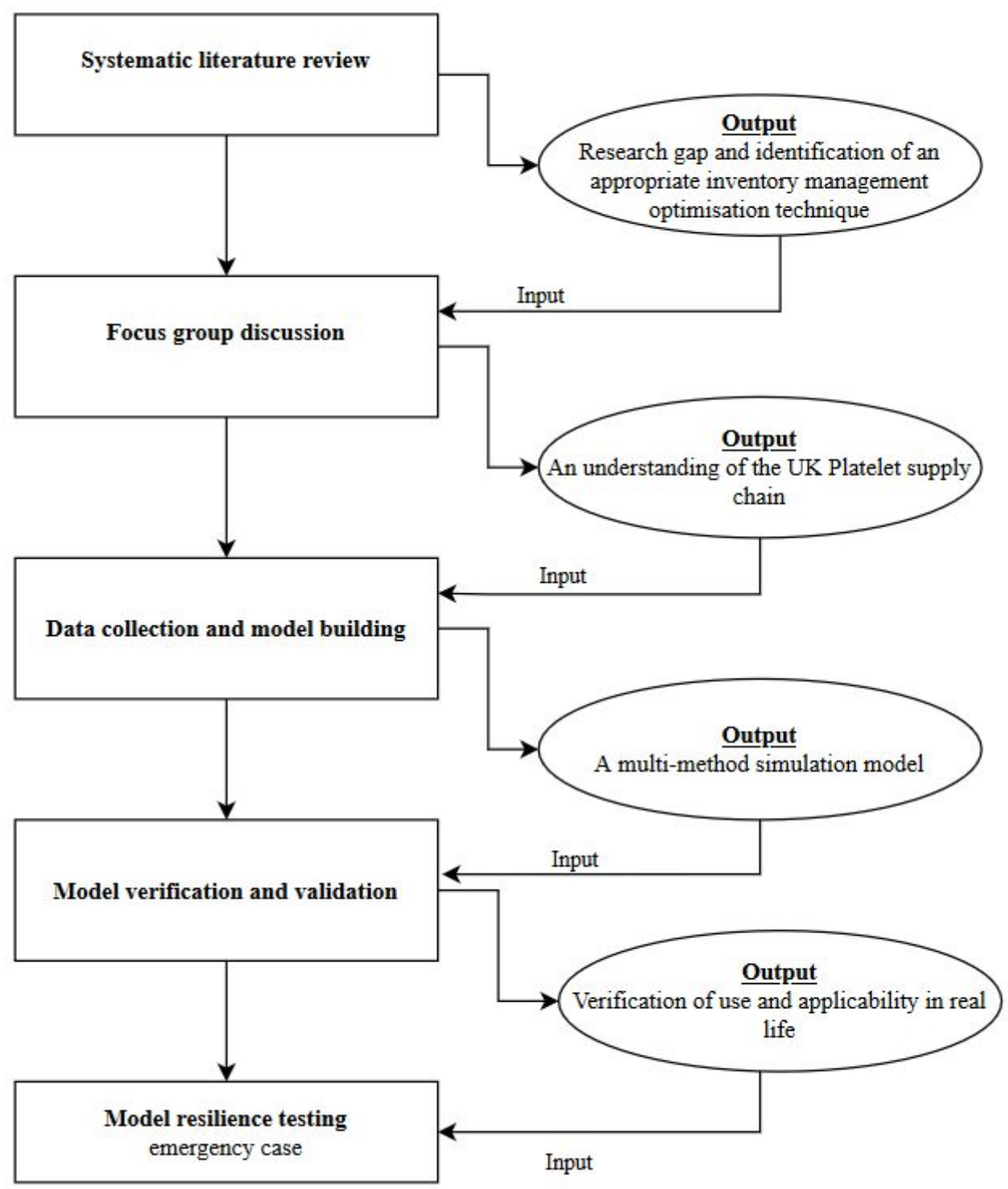

Figure 1: Overview of the research process (Source: Authors) 


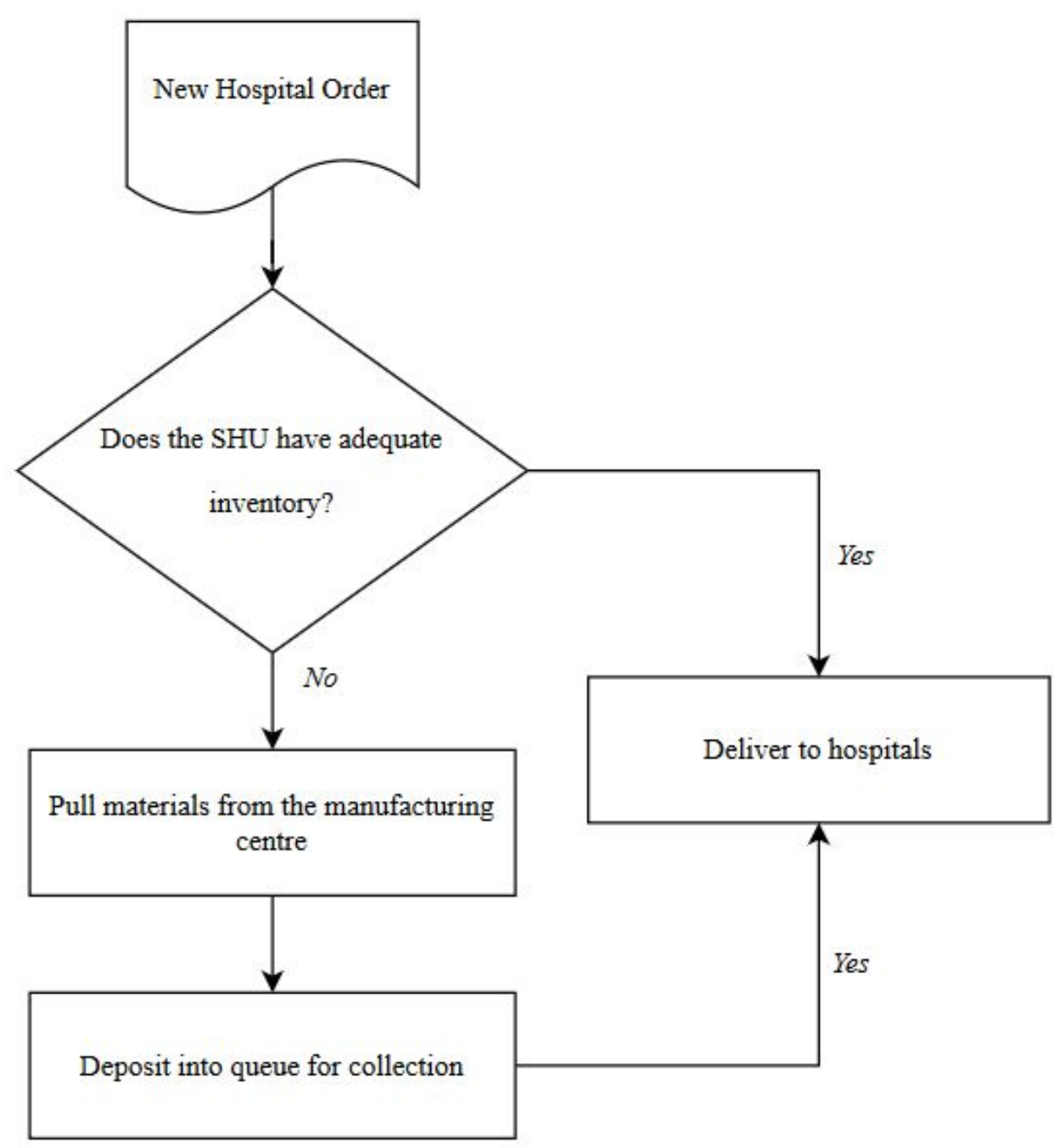

Figure 2: Model pull logic (Source: Authors) 


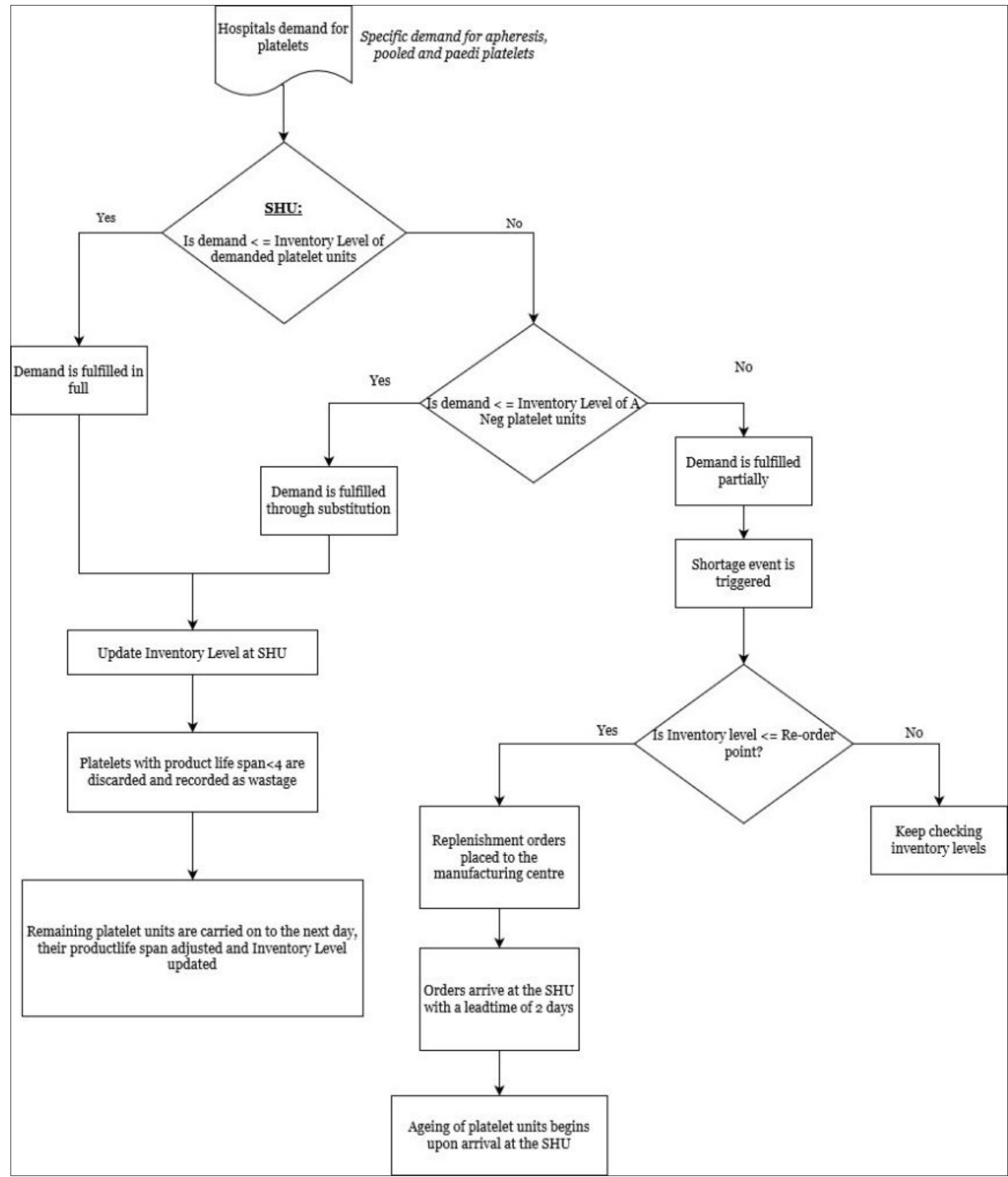

Figure 3: Model behaviour flowchart (Source: Authors) 


\section{List of tables}

Table 1: Model validation- Comparison of actual data to simulation results ........................11

Table 2: Simulation Results for Daily Inventory Levels ................................................12

Table 3: Analysis of SHU outdated (expired) units ..........................................................13 
Table 1: Model validation-Comparison of actual data to simulation results

\begin{tabular}{|c|c|c|c|c|c|c|}
\hline \multicolumn{7}{|c|}{ Apheresis platelets } \\
\hline & \multicolumn{2}{|c|}{ Actual } & \multicolumn{2}{|c|}{ Simulated } & \multicolumn{2}{|c|}{ Variances } \\
\hline $\begin{array}{c}\text { Blood } \\
\text { type }\end{array}$ & $\begin{array}{c}\text { Inventory } \\
\text { level }\end{array}$ & Wastages & $\begin{array}{c}\text { Inventory } \\
\text { level }\end{array}$ & Wastages & $\begin{array}{c}\text { Inventory } \\
\text { level }\end{array}$ & Wastages \\
\hline A- & 14 & 5 & 13 & 3 & 1 & 2 \\
\hline A+ & 35 & 14 & 34 & 12 & 1 & 2 \\
\hline AB- & 1 & 0 & 1 & 0 & 0 & 0 \\
\hline $\mathbf{A B}+$ & 3 & 1 & 3 & 0 & 0 & 1 \\
\hline B- & 2 & 1 & 1 & 0 & 1 & 1 \\
\hline B+ & 10 & 5 & 9 & 5 & 1 & 0 \\
\hline O- & 5 & 0 & 7 & 1 & 2 & 1 \\
\hline $\mathbf{O +}$ & 26 & 10 & 27 & 9 & 1 & 1 \\
\hline
\end{tabular}


Table 2: Simulation Results for Daily Inventory Levels

\begin{tabular}{|c|c|c|c|c|c|c|c|c|c|}
\hline \multirow[t]{2}{*}{$\begin{array}{l}\text { Blood } \\
\text { type }\end{array}$} & \multicolumn{3}{|c|}{ Apheresis } & \multicolumn{3}{|c|}{ Pooled } & \multicolumn{3}{|c|}{ Paedi } \\
\hline & $\begin{array}{l}\text { Model } \\
\text { results }\end{array}$ & $\begin{array}{l}\text { Actual } \\
\text { target }\end{array}$ & $\begin{array}{l}\% \text { over/under } \\
\text { stock }\end{array}$ & $\begin{array}{l}\text { Model } \\
\text { results }\end{array}$ & $\begin{array}{l}\text { Actual } \\
\text { target }\end{array}$ & $\%$ over/under stock & $\begin{array}{l}\text { Model } \\
\text { results }\end{array}$ & $\begin{array}{l}\text { Actual } \\
\text { target }\end{array}$ & $\begin{array}{l}\text { \%over/under } \\
\text { stock }\end{array}$ \\
\hline A- & 12 & 14 & $14 \%$ overstock & 7 & 12 & $42 \%$ overstock & 5 & 1 & $400 \%$ understock \\
\hline AB- & - & 1 & $100 \%$ overstock & - & 1 & $100 \%$ overstock & 0 & 1 & $100 \%$ overstock \\
\hline $\mathbf{A B}+$ & 3 & 3 & $0 \%$ & 1 & 2 & $50 \%$ overstock & 0 & 1 & $100 \%$ overstock \\
\hline B- & 1 & 2 & $50 \%$ overstock & 1 & 2 & $50 \%$ overstock & 0 & 1 & $100 \%$ overstock \\
\hline O- & 9 & 5 & $80 \%$ understock & 7 & 4 & $75 \%$ understock & 3 & 1 & $200 \%$ understock \\
\hline $\mathbf{O +}$ & 28 & 26 & $8 \%$ understock & 27 & 22 & $23 \%$ understock & 1 & 3 & $67 \%$ overstock \\
\hline
\end{tabular}


Table 3: Analysis of SHU outdated (expired) units

\begin{tabular}{|c|c|c|c|c|c|c|c|c|c|}
\hline $\begin{array}{l}\text { Blood } \\
\text { type }\end{array}$ & & Aphere & & & Poole & & & Paed & \\
\hline$\$$ & $\begin{array}{l}\text { Actual } \\
\text { units }\end{array}$ & $\begin{array}{l}\text { Simulated } \\
\text { units }\end{array}$ & $\begin{array}{l}\text { \% } \\
\text { improvement }\end{array}$ & $\begin{array}{l}\text { Actual } \\
\text { units }\end{array}$ & $\begin{array}{l}\text { Simulated } \\
\text { units }\end{array}$ & $\begin{array}{l}\% \\
\text { improvement }\end{array}$ & $\begin{array}{l}\text { Actual } \\
\text { units }\end{array}$ & $\begin{array}{l}\text { Simulated } \\
\text { units }\end{array}$ & $\begin{array}{l}\text { \% } \\
\text { improvement }\end{array}$ \\
\hline${ }_{1}^{9} \mathrm{~A}-$ & 5 & 0 & $100 \%$ & 6 & - & $100 \%$ & 5 & 0 & $100 \%$ \\
\hline${ }_{3}^{2} \mathrm{~A}+$ & 14 & 4 & $71 \%$ & 16 & 4 & $75 \%$ & 13 & 0 & $100 \%$ \\
\hline$\left\{\begin{array}{l}4 \\
5 \mathrm{AB}- \\
6\end{array}\right.$ & 0 & 0 & $0 \%$ & 0 & 0 & $0 \%$ & 0 & 0 & $0 \%$ \\
\hline $8 \mathrm{AB}+$ & 1 & 0 & $100 \%$ & 1 & - & $100 \%$ & 2 & 0 & $100 \%$ \\
\hline 200 & 1 & 0 & $100 \%$ & 1 & - & $100 \%$ & 1 & 0 & $100 \%$ \\
\hline 22 & 5 & 1 & $78 \%$ & 5 & 1 & $81 \%$ & 6 & 1 & $83 \%$ \\
\hline $26-$ & 2 & 1 & $56 \%$ & 3 & - & $100 \%$ & 3 & 0 & $100 \%$ \\
\hline $27 \quad 0+$ & 10 & 4 & $61 \%$ & 12 & 3 & $75 \%$ & 14 & 0 & $100 \%$ \\
\hline
\end{tabular}

